Article

\title{
Improved NOAA-20 Visible Infrared Imaging Radiometer Suite Day/Night Band Image Quality by Upgraded Gain Calibration
}

\author{
Yalong Gu ${ }^{1, *}$, Slawomir Blonski ${ }^{1} \oplus$, Wenhui Wang ${ }^{2}{ }^{\oplus}$, Sirish Uprety ${ }^{2}$, Taeyoung Choi ${ }^{1}$, Xi Shao $^{2} \oplus$, Bin Zhang ${ }^{2}$ \\ and Changyong $\mathrm{Cao}^{3}$ (D) \\ 1 Global Science and Technology, Greenbelt, MD 20770, USA; slawomir.blonski@noaa.gov (S.B.); \\ taeyoung.choi@noaa.gov (T.C.) \\ 2 Cooperative Institute for Satellite Earth System Studies (CISESS), University of Maryland, College Park, \\ MD 20740, USA; wenhui.wang@noaa.gov (W.W.); sirish.uprety@noaa.gov (S.U.); xi.shao@noaa.gov (X.S.); \\ bin.zhang@noaa.gov (B.Z.) \\ 3 Center for Satellite Applications and Research, NOAA/NESDIS, College Park, MD 20740, USA; \\ changyong.cao@noaa.gov \\ * Correspondence: yalong.gu@noaa.gov; Tel.: +1-301-683-2563
}

\section{check for} updates

Citation: Gu, Y.; Blonski, S.; Wang, W.; Uprety, S.; Choi, T.; Shao, X.;

Zhang, B.; Cao, C. Improved

NOAA-20 Visible Infrared Imaging Radiometer Suite Day/Night Band Image Quality by Upgraded Gain Calibration. Remote Sens. 2021, 13, 2509. https://doi.org/10.3390/ rs13132509

Academic Editor:

Ferdinando Nunziata

Received: 21 May 2021

Accepted: 23 June 2021

Published: 26 June 2021

Publisher's Note: MDPI stays neutral with regard to jurisdictional claims in published maps and institutional affiliations.

Copyright: (c) 2021 by the authors. Licensee MDPI, Basel, Switzerland. This article is an open access article distributed under the terms and conditions of the Creative Commons Attribution (CC BY) license (https:// creativecommons.org/licenses/by/ $4.0 /)$.
Abstract: Due to complex radiometric calibration, the imagery collected by the Day/Night Band (DNB) of the Visible Infrared Imaging Radiometer Suite (VIIRS) onboard the Suomi National Polar Partnership (Suomi-NPP) and the NOAA-20 follow-on satellite is subject to artifacts such as striping, which eventually affect Earth remote sensing applications. Through comprehensive analysis using the NOAA-20 VIIRS DNB prelaunch-test and on-orbit data, it is revealed that the striping results from flaws in the calibration process. In particular, a discrepancy between the low-gain stage (LGS) Earth view (EV) gain and the onboard calibrator solar diffuser view gain makes the operational LGS gain coefficients of a few aggregation modes and detectors biased. Detector nonlinearity at low radiance level also induces errors to the mid-gain stage (MGS) and high-gain stage (HGS) gain through the biased gain ratios. These systematic errors are corrected by scaling the operational LGS gains using the factors derived from the NOAA-20 VIIRS DNB prelaunch test data and by adopting linear regression for evaluating the gain ratios. Striping in the NOAA-20 VIIRS DNB imagery is visibly reduced after the upgraded gain calibration process was implemented in the operational calibration.

Keywords: NOAA-20; VIIRS DNB; radiometric calibration; detector nonlinearity; striping

\section{Introduction}

The day/night band (DNB) is a panchromatic visible and infrared band of the Visible Infrared Imaging Radiometer Suite (VIIRS) onboard the Suomi National Polar-Orbiting Partnership (Suomi-NPP) and NOAA-20 satellites. It consists of three separate detection channels with the same spectral range, which are the low-gain stage (LGS) for daytime scenes, mid-gain stage (MGS) for twilight scenes and high-gain stage (HGS) for nighttime scenes. Data recorded by three gain stages are combined onboard the satellite into the DNB data. Known for near-constant spatial resolution and extreme sensitivity to low light, the DNB opens a new era of Earth remote sensing at nighttime [1,2]. Examples of such applications include monitoring of anthropogenic activities [3], automated fishing boat detection [4], retrieval of nighttime aerosol characteristics [5], and socio-economic studies [6]. Science-grade global nighttime light products have been successfully derived from the DNB observations of the Earth at nighttime by applying several corrections such as lunar, terrain, and snow $[7,8]$. They enable wide variety of applications for explicit measurements of human activities in a timely and spatially-extensive manner $[9,10]$. The DNB data are also used to create the near-constant contrast (NCC) imagery [11], a more user-friendly product that has found widespread use for supporting weather forecasting, especially in the polar regions including Alaska [12]. 
As most DNB applications are image based, high quality DNB imagery is demanded. In fact, the primary objective of the DNB is to obtain imagery without major artifacts such as striping [13]. The NCC imagery product derived from the DNB data is one of the key performance parameters of the VIIRS [12]. Due to the three-gain stage design that covers an extremely wide dynamic range, radiometric calibration of the DNB is complex. The LGS gain is calibrated by the onboard solar diffuser when it is fully illuminated by the Sun. The LGS calibration is then transferred to the MGS and HGS gains through the MGS/LGS and HGS/MGS gain ratios derived from the Earth observations collected in twilight regions. The complicated calibration process makes the DNB imagery subject to artifacts such as striping. Striping has been found in both daytime and nighttime operational DNB imagery since the launch of Suomi-NPP in October 2011 [14]. Because of striping and other non-uniformities, the data collected at high scan angles, that is about $11 \%$ of the entire Suomi-NPP VIIRS DNB nighttime data, are discarded when creating the global nighttime light dataset [15].

The second VIIRS DNB onboard NOAA-20 satellite has been in operation since the launch in November 2017. A significant difference compared to the Suomi-NPP VIIRS DNB is the special aggregation scheme known as Option 21 [16]. It extends aggregation mode 21 up to high scan angles at the beginning and the end of a scan, in place of modes 22-32 of the aggregation scheme adopted by the Suomi-NPP VIIRS DNB. Such change is necessary to mitigate significant nonlinearity over low radiances in the high aggregation modes discovered during the prelaunch testing [17]. It was expected that striping in the NOAA-20 VIIRS DNB imagery would be smaller than in its Suomi-NPP counterpart as the high aggregation zones are more susceptible to striping. However, striping appears in the NOAA-20 VIIRS DNB imagery again, both day and night. In particular, obvious striping is observed in aggregation zone 21 of the nighttime imagery. According to Option 21 , aggregation zone 21 occupies about $30 \%$ of a DNB image. Such striping significantly degrades the quality of the NOAA-20 VIIRS DNB imagery.

Striping in a remote sensing image generally refers to variation among detector responses due to imperfect calibration. In recent years, several efforts have been devoted to evaluating the causes of striping in the Suomi-NPP VIIRS DNB imagery. It is reported that residual stray light, reflectance difference between two sides of the half angle mirror (HAM), electronic effects, and detector nonlinearity are major causes of the striping [18]. Two updated methods, which are the automatic correction based on light contamination ranking index [19] and the fused correction combined from the historic stray light estimates [20], were developed recently to improve stray light correction in twilight regions. Although an algorithm based on the histogram matching method was proposed to de-stripe DNB observations collected during both day and night, it is a post-processing step to the operational production of the calibrated DNB radiances that requires additional time [18]. Methods for striping correction that can be implemented in the operational DNB calibration are preferred.

In this paper, we presented an upgraded gain calibration processing method developed through a comprehensive analysis of the NOAA-20 VIIRS DNB prelaunch test data as well as the data collected on orbit. It is revealed that the operational LGS gain coefficients of a few aggregation modes and some detectors are biased because of differences between the LGS Earth View (EV) gain and the solar diffuser view gain. Detector nonlinearity at low radiance levels also induces errors to the MGS and HGS gains through the biased gain ratios. These systematic errors are corrected by scaling the operational LGS gain using factors derived from the NOAA-20 VIIRS DNB prelaunch test data and by adopting linear regression for evaluating the gain ratios. Striping in the NOAA-20 VIIRS DNB imagery is significantly reduced after the upgraded gain calibration process was implemented in the operational calibration.

The paper is organized as follows. The original DNB gain calibration process is reviewed in Section 2. Analysis of systematic errors in the original process and the corresponding upgraded process are presented in Section 3. Examples of improved NOAA-20 
VIIRS DNB imagery with reduced striping are shown in Section 4. Conclusions are given in Section 5.

\section{Overview of Original DNB Gain Calibration}

The DNB sensor is a temperature-controlled charge-coupled device (CCD) composed of four detector arrays named as High-Gain Stage A (HGA), High-Gain Stage B (HGB), MGS and LGS, whose sizes (track $\times$ scan) are $672 \times 250,672 \times 250,672 \times 3$, and $672 \times 1$, respectively [21]. The design of the duplicated high gain stages is for eliminating the effects induced by high energy particle radiation in the space environment. On orbit, the DNB collects data through a rotating telescope assembly (RTA) that successively scans four windows of view: EV, blackbody (BB), solar diffuser (SD) and space view (SV). The latter three are known as the onboard calibrators (OBCs) designed for the VIIRS onorbit calibration [22]. In order to minimize the growth of the pixel size and the ground sampling intervals with the scan angle, known as the bowtie effect, the entire EV window is divided into a number of aggregation zones on each side of nadir. The aggregation zones are a function of scan position at which different number of detectors is grouped according to the specific aggregation scheme [23]. After aggregation, the size of a single-scan DNB EV data is $16 \times 4064$ (track $\times$ scan). The 16 along-track pixels are created by on-board aggregation of up to 672 along-track detectors. Unless otherwise specified, the actual detectors are named as "subpixels", while the term "detector" used in the rest of the paper refers to the 16 virtual along-track detectors, both following the VIIRS nomenclature [21].

The DNB's Earth observations are radiometrically calibrated by the following linear equation:

$$
\mathrm{L}=\frac{\mathrm{G} \times\left(\mathrm{DN}-\mathrm{DN}_{0}\right)}{\mathrm{RVS}_{\mathrm{EV}}}
$$

where the EV response versus scan (RVS) accounts for the scan angle dependency of EV signal reflection from the HAM. Dark offset $\left(\mathrm{DN}_{0}\right)$ and gain coefficient $(\mathrm{G})$ are two key parameters for converting the instrument measured digital number (DN) to radiance (L). The three gain stages measure radiance of Earth scenes independently. Given the strength of the incident radiance, measurement from one gain stage is selected as the output of the DNB according to a predefined gain selection logic [21]. Therefore, the dark offsets and gains of the LGS, MGS, and HGS are determined separately. The dark offsets of all three gain stages are updated monthly through the combined use of the onboard BB data and the nighttime measurements over the Pacific Ocean during new moon using the VIIRS recommended operating procedures (VROPs) [24-26].

Determination of the DNB gain coefficients is relatively complicated due to the different dynamic ranges of the three gain stages. The LGS gain is calibrated using the onboard SD when it is fully illuminated by the Sun, expressed by the following equation:

$$
\mathrm{G}_{\mathrm{LGS}}=\frac{\mathrm{L}_{\mathrm{SD}} \times \mathrm{RVS}_{\mathrm{SD}}}{\mathrm{dn}_{\mathrm{SD}}}
$$

where $\mathrm{dn}_{\mathrm{SD}}$ is the LGS SD response corrected by the offset which is derived from the LGS SV data. RVS $_{\mathrm{SD}}$ characterizes scan angle dependency when viewing the SD. $\mathrm{L}_{\mathrm{SD}}$ is the expected solar radiance reflected by the SD, which is calculated by the following equation [21]:

$$
\mathrm{L}_{\mathrm{SD}}=\int \mathrm{H}_{\mathrm{DNB}} \times \mathrm{RSR}_{\mathrm{LGS}} \times \mathrm{E}_{\mathrm{sun}} \times \mathrm{BRDF} \times \tau_{\mathrm{SDS}} \times \frac{\cos \left(\theta_{\text {inc }}\right)}{\mathrm{d}^{2}} \mathrm{~d} \lambda,
$$

where $\mathrm{H}$ is the $\mathrm{H}$-factor characterizing the degradation of the SD within the DNB spectral range, $\mathrm{E}_{\text {sun }}$ is the solar spectral irradiance, $\mathrm{BRDF}$ is the bidirectional reflectance distribution function of the SD determined before the degradation occurred, $\tau_{\mathrm{SDS}}$ is the transmission function of the screen in front of the $S D$, RSR $_{\mathrm{LGS}}$ is the relative spectral response function of the LGS, $\theta_{\text {inc }}$ is the incidence angle of sun light arriving at the SD, and $\mathrm{d}$ is the distance between the Sun and the satellite in the astronomical units. Because the number of grouped 
subpixels is aggregation mode dependent, the LGS gain is determined per aggregation mode. Unlike the DNB EV data which include all aggregation modes in a scan, the DNB $\mathrm{OBC}$ data $(\mathrm{BB}, \mathrm{SD}$, and $\mathrm{SV})$ are only recorded in one aggregation mode per scan. The SD is fully illuminated by the Sun only for a few minutes on each orbit, and two orbits are currently required to complete the LGS calibration for all aggregation modes. After a careful examination of the SD observation profile of the Sun, it was determined that the time period to collect the SD data for DNB can be expanded, allowing the completion of LGS calibration for all aggregation modes within one orbit [27]. The proposed approach would require extensive modifications to the current DNB calibration processing. It has not been implemented in the operational software at this time.

Because the MGS and HGS are saturated when viewing the SD during the solar illumination period, their gain coefficients are obtained indirectly by multiplying the LGS gain with the gain ratios of MGS/LGS and HGS/MGS, i.e.,

$$
\begin{gathered}
\mathrm{G}_{\text {MGS }}=\mathrm{G}_{\text {MGS } / \text { LGS }} \times \mathrm{G}_{\text {LGS }} \\
\mathrm{G}_{\text {HGS }}=\mathrm{G}_{\text {HGS } / \text { MGS }} \times \mathrm{G}_{\text {MGS } / \text { LGS }} \times \mathrm{G}_{\text {LGS }},
\end{gathered}
$$

where $G_{M G S / L G S}$ and $G_{H G S / M G S}$ are the quantities to be evaluated. Based on the assumption of simultaneous measurement of the same incident radiance by the three gain stages, namely

$$
\begin{aligned}
& \mathrm{G}_{\mathrm{LGS}} \times \mathrm{dn}_{\mathrm{LGS}}=\mathrm{G}_{\mathrm{MGS}} \times \mathrm{dn}_{\mathrm{MGS}}, \\
& \mathrm{G}_{\mathrm{MGS}} \times \mathrm{dn}_{\mathrm{MGS}}=\mathrm{G}_{\mathrm{HGS}} \times \mathrm{dn}_{\mathrm{HGS}},
\end{aligned}
$$

we have

$$
\begin{aligned}
\mathrm{G}_{\mathrm{MGS} / \mathrm{LGS}} & =\frac{\mathrm{dn}_{\mathrm{LGS}}}{\mathrm{dn}_{\mathrm{MGS}}}, \\
\mathrm{G}_{\mathrm{HGS} / \mathrm{MGS}} & =\frac{\mathrm{dn}_{\mathrm{MGS}}}{\mathrm{d} n_{\mathrm{HGS}}},
\end{aligned}
$$

where $\mathrm{dn}_{\mathrm{LGS}}, \mathrm{dn}_{\mathrm{MGS}}$, and $\mathrm{dn}_{\mathrm{HGS}}$ are the dark offset corrected responses in the unit of DN. When deriving Equation (6) using Equation (1), the RVS term cancels out because of the same scan angle of the simultaneous measurements. DNB EV measurements over twilight regions include many pairs of $d_{n_{L G S}}$ and $d n_{\text {MGS }}$ for evaluating $G_{M G S / L G S}$ and pairs of $\mathrm{dn}_{\text {MGS }}$ and $\mathrm{dn}_{\mathrm{HGS}}$ for evaluating $\mathrm{G}_{\mathrm{HGS} / \mathrm{MGS}}$. An example is shown in Figure 1 where the NOAA-20 VROP data collected on 8 October 2018 were used. From the scatter plot in Figure $1 \mathrm{a}$, it can be seen that $\mathrm{dn}_{\mathrm{LGS}}$ and $\mathrm{dn}_{\mathrm{MGS}}$ follow a linear relationship. Only the data pairs whose $d_{\text {LGS }}$ is above the noise level and dn $n_{M G S}$ is not saturated are selected (red dots in Figure 1a). The ratios of the selected pairs of $d_{\text {LGS }}$ and $d_{n_{M G S}}$ form an ensemble of MGS/LGS gain ratios (Figure 1b). After removing outliers by a filtering scheme, $\mathrm{G}_{\text {MGS/LGS }}$ for a given aggregation mode and detector is obtained. Gain ratios are updated monthly using the data collected by the VROPs [24].

The radiometrically calibrated DNB products, known as the DNB sensor data records (SDRs), are generated by the Interface Data Processing Segment (IDPS). They are available to the public in the NOAA Comprehensive Large Array-data Stewardship System (CLASS). The NASA Land Science Investigator-led Processing System (Land SIPS) provides another version of the calibrated DNB radiances known as the DNB level 1 product, which are calibrated by its own algorithm [28]. In this paper, we focus on the gain calibration process that supports the DNB operational calibration at IDPS. 

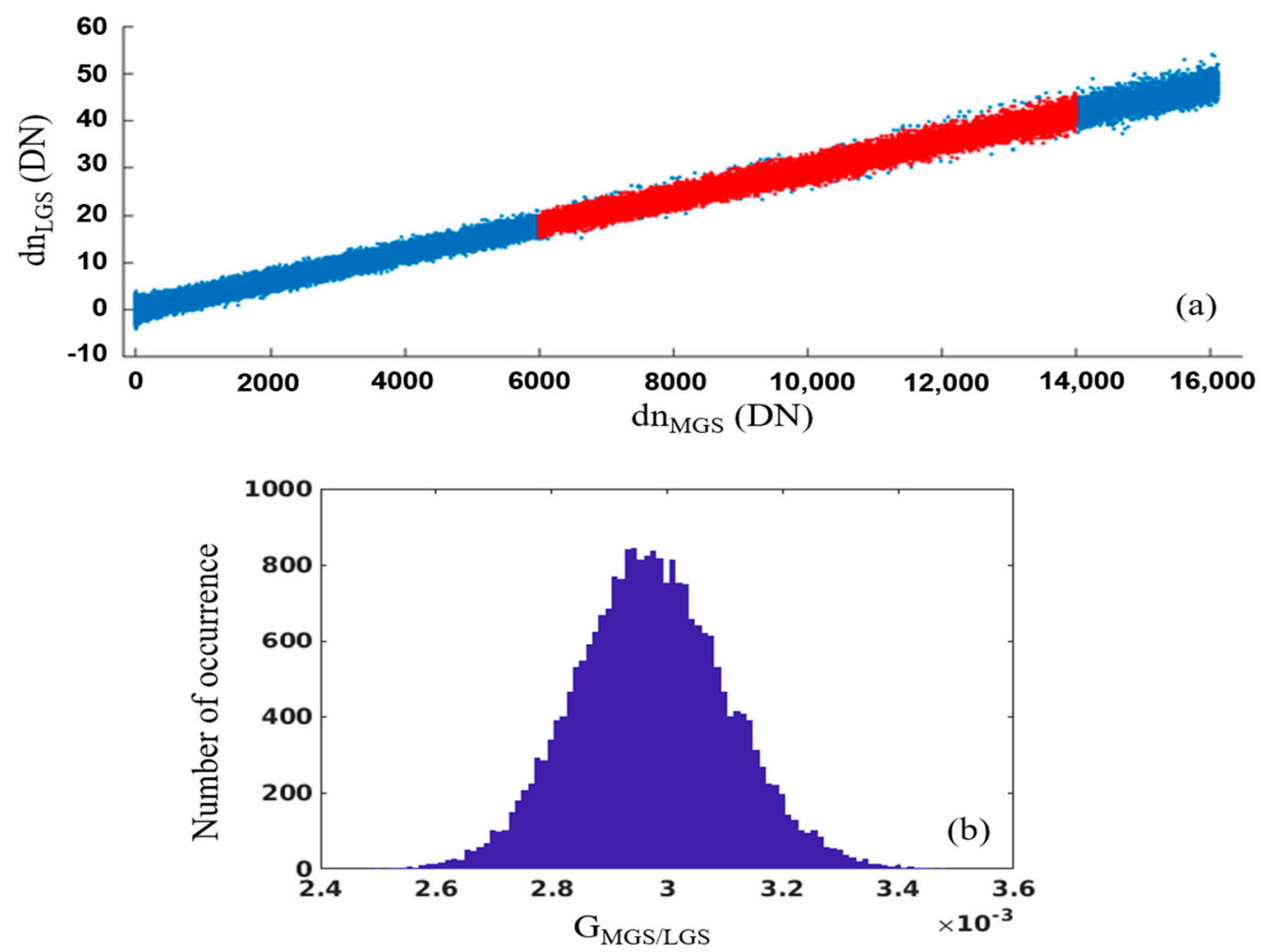

Figure 1. (a) Scatter plot of $d n_{\text {LGS }}$ and $d n_{\text {MGS }}$ collected during a NOAA-20 VROP between 8:38 and 8:54 UTC on 8 October 2018. The red part is used for $G_{M G S / L G S}$ determination. (b) Histogram of the gain ratios calculated by the selected pairs of $\mathrm{dn}_{\mathrm{LGS}}$ and $\mathrm{dn}_{\mathrm{MGS}}$ [the red part in (a)] using Equation (6a). Data for aggregation mode 21 and detector 9 are shown.

\section{Analysis of Systematic Errors in Original Gain Calibration Process}

VIIRS is categorized as a whisk-broom scanning radiometer which collects EV data by the RTA sweeping in the scan direction perpendicular to the spacecraft flight path known as the track direction. The DNB sensor's 16 detectors that align along the track direction record 4064 frames of data through the EV window of a single-scan. As the spacecraft flies forward, the EV data collected by consecutive scans are stitched together along the track direction to form continuous Earth observation. Usually, every 48 consecutive scans are grouped together as the minimum partition known as a granule. The DNB image size of one granule is $768 \times 4064$ (track $\times$ scan) pixels.

By convention, a DNB image is displayed in a way that the scan direction is horizontal and the track direction is vertical. Striping refers to bright or dark horizontal streaks shown in radiometrically calibrated DNB imagery. Figure 2a shows a NOAA-20 VIIRS DNB daytime image over Antarctica. It can be clearly seen that dark streaks appear in both the right and left side of the figure. Bright streaks which are less significant are also found next to these dark streaks, where the boundaries of different striping patterns are coincident with the aggregation zone boundaries. An example of NOAA-20 VIIRS DNB nighttime image is shown in Figure 2b, which is over the Midwestern United States. The large bright spot in the middle of the figure is the Chicago metropolitan area. Most pixels in the figure are in aggregation zone 21 where significant dark streaks are present. 

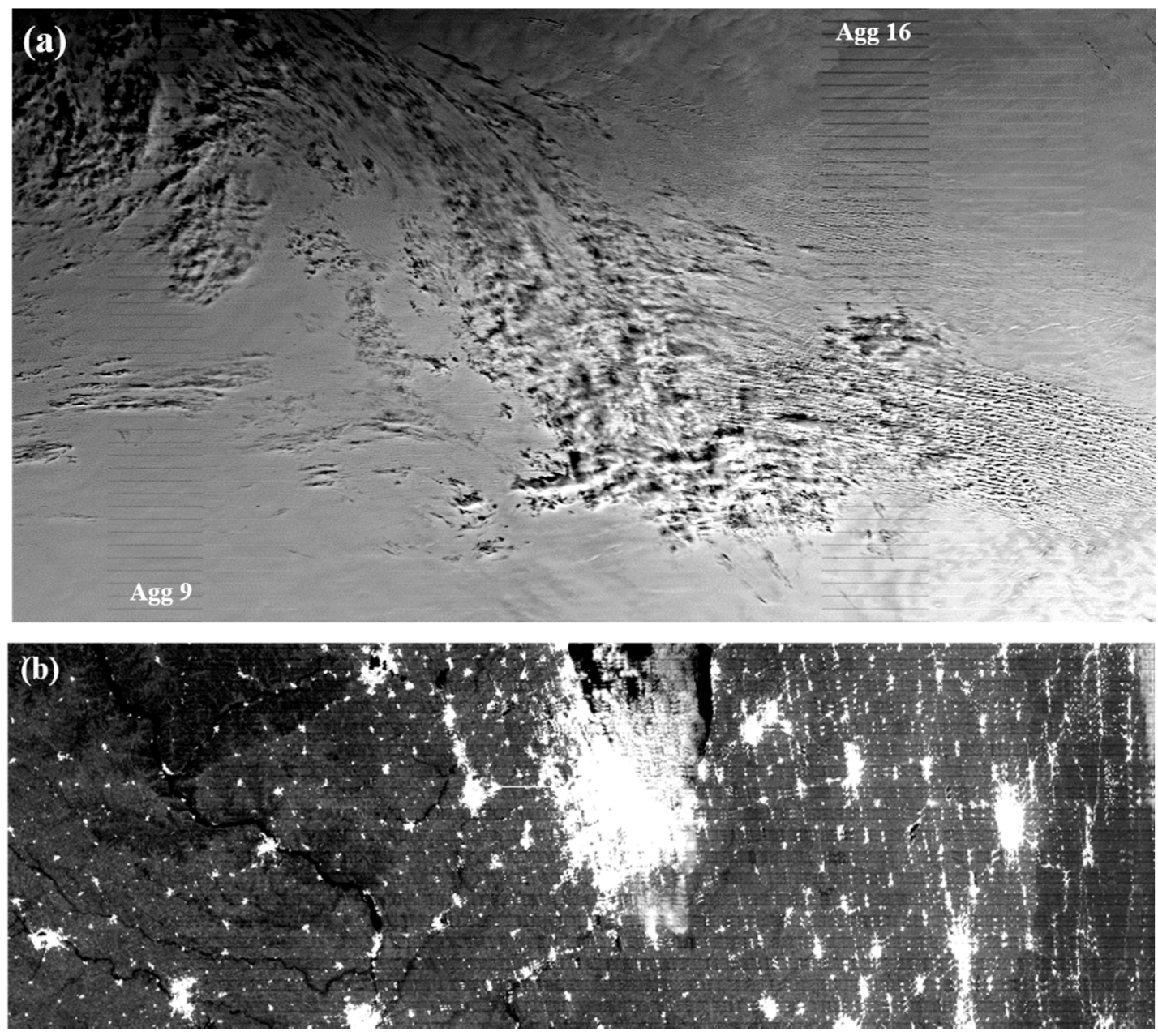

Figure 2. (a) NOAA-20 VIIRS DNB daytime radiance image recorded over Antarctica at 8:34 UTC, 14 December 2020, where aggregation zones 9 and 16 are marked. The $768 \times 768$ (track $\times$ scan) pixels are in the right side of the granule (aggregation zones 8-19). The range of radiance is from $4.83 \times 10^{-3} \mathrm{~W} / \mathrm{cm}^{2}$-sr to $1.01 \times 10^{-2} \mathrm{~W} / \mathrm{cm}^{2}$-sr. (b) NOAA-20 VIIRS DNB nighttime radiance image recorded over the Midwestern United States at 8:56 UTC, October 24, 2018. The $288 \times 864$ (track $\times$ scan) pixels are in the upper right side of the granule. The range of radiance is from $1.73 \times 10^{-9} \mathrm{~W} / \mathrm{cm}^{2}-\mathrm{sr}$ to $2.91 \times$ $10^{-6} \mathrm{~W} / \mathrm{cm}^{2}$-sr.

The striping patterns shown in Figure 2 are typical examples of the striping issue of the operational NOAA-20 VIIRS DNB imagery. They are present in certain aggregation zones since the beginning of the mission, indicating systematic errors in the radiometric calibration process. As illustrated by Equation (1), radiance is converted from instrument measurement by dark offset and RVS correction and then multiplication of gain coefficient. The first step to pinpoint the root cause of striping is to investigate the dark offset and RVS corrected DN image, i.e., $\left(\mathrm{DN}-\mathrm{DN}_{0}\right) /$ RVS. Figure 3 shows the dark offset and RVS corrected $\mathrm{DN}$ images which correspond to the radiance images in Figure 2. Multiple bands in Figure 3a illustrate the locations of the involved aggregation zones. Their brightness varies as the measured $\mathrm{DN}$ value is proportional to the number of subpixels grouped in an aggregation zone. The striping patterns present in Figure 2 are absent in Figure 3. This indicates that error in gain coefficient is the cause of striping. The original gain calibration process will be analyzed in the following subsections. 

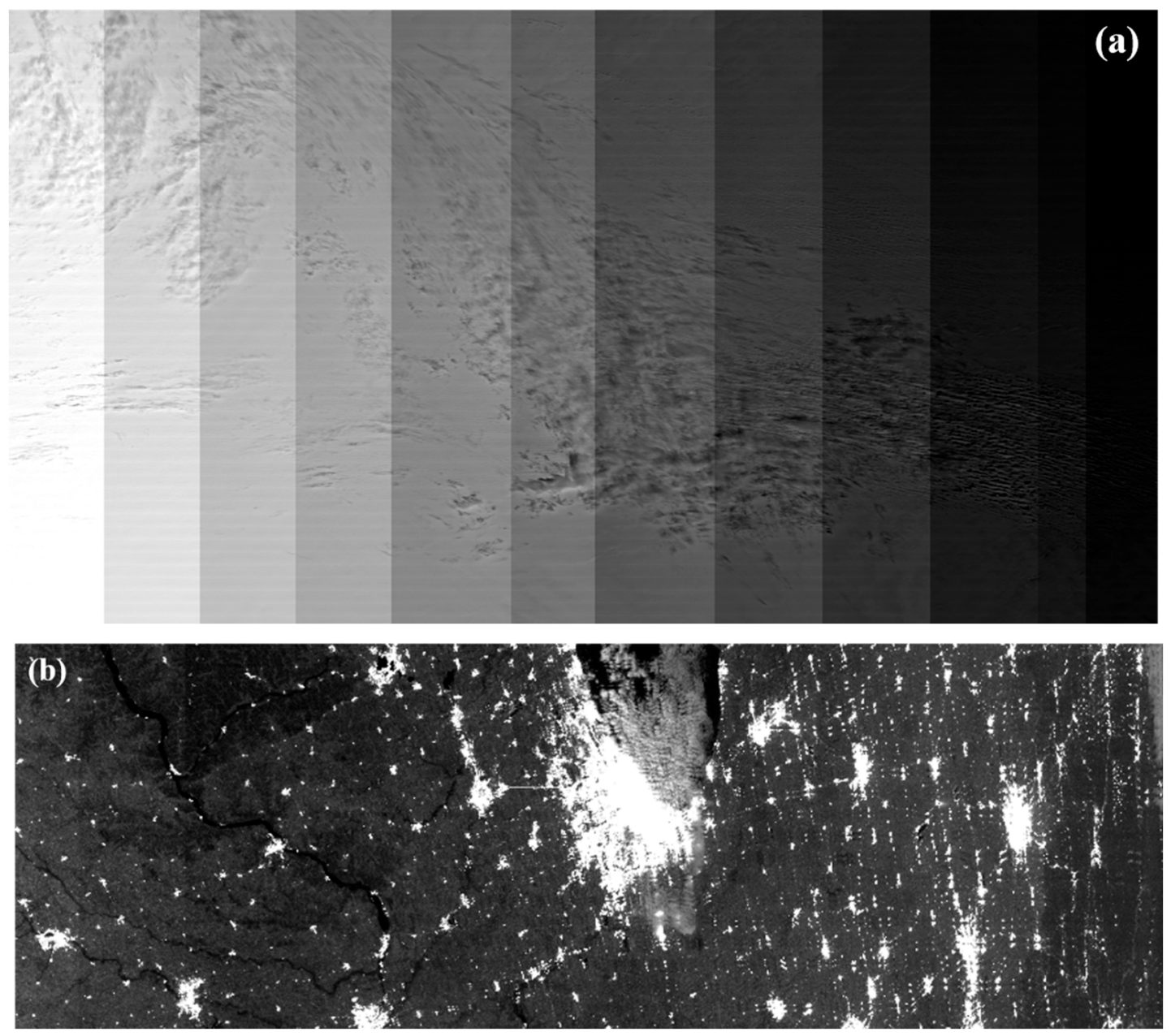

Figure 3. Gain correction free images of Figure 2. (a) Dark offset and RVS corrected DN image of Figure 2a. (b) Dark offset and RVS corrected DN image of Figure $2 b$.

\subsection{Discrepancy between LGS EV and SD View Responses}

As introduced in Section 2, the LGS gain which is used for calibrating the EV data is determined by the onboard SD view data. Such a methodology assumes that the gain coefficients of the two views' measurements are the same. It is known that the DNB electronic timing is different in the OBC views relative to the EV [21]. DNB EV dark offsets of entire aggregation modes cannot be derived using the $\mathrm{OBC}$ data due to such difference [29]. Considering the typical striping pattern of the NOAA-20 VIRS DNB daytime imagery shown in Figure 2a, it is reasonable to question whether the two views' LGS gains are the same for all aggregation modes.

Investigation of consistency between the LGS EV and SD view radiometric responses requires that the two views are illuminated by the same light source whose spectral radiance is well characterized. There is unfortunately no such opportunity once the satellite has been deployed in space. However, a comprehensive pre-launch test was conducted for the VIIRS DNB onboard the NOAA-20, which is known as the Joint Polar Satellite System 1 (JPSS-1) before the launch $[17,30]$. During the test for radiometric characterization, the RTA was locked to view a spherical integrating source named SIS-100 through the EV port [31]. The DNB EV, BB, SD and SV responses to the source were recorded in sequence. The radiometric characterization was performed at several discrete radiance levels covering the entire dynamic range of the DNB's all three gain stages. Through turning on selective lamps of the SIS-100, a particular radiance level was obtained while the spectrum of the corresponding output radiance was measured by a well-established procedure [17]. 
The prelaunch LGS EV gain was determined by a linear fit of the test data whose radiances were less than the LGS's maximum radiance and greater than the radiance when the stage transition from MGS to LGS occurs [17]. Because of no constant term in the operational linear calibration model for the DNB (Equation (1)), the linear fit was set to pass through the origin. Another version of the prelaunch LGS EV gain by a linear fit allowing nonzero constant term was also derived for the purpose of comparison. Their relative difference, shown in Figure 4 , is less than $0.1 \%$ for most of the aggregation modes and detectors, while the differences of the rest are less than $0.3 \%$. Therefore, the calibration model given in Equation (1) is appropriate for the DNB LGS. Considering the negligible impact of such a slight difference on the specified DNB calibration uncertainty, which is $5-10 \%$ for the LGS, $10-30 \%$ for the MGS, and 30-100\% for the HGS [21], the version of prelaunch LGS EV gain obtained by the linear fit without constant term was adopted in this paper. In order to simulate the on-orbit calibration using the SD, a specific dataset of the test, whose output radiance within the LGS spectral range is similar to the in-band solar radiance when the LGS views the Sun via the SD on orbit, was selected to calculate the prelaunch LGS EV gain, using an equation similar to Equation (2).

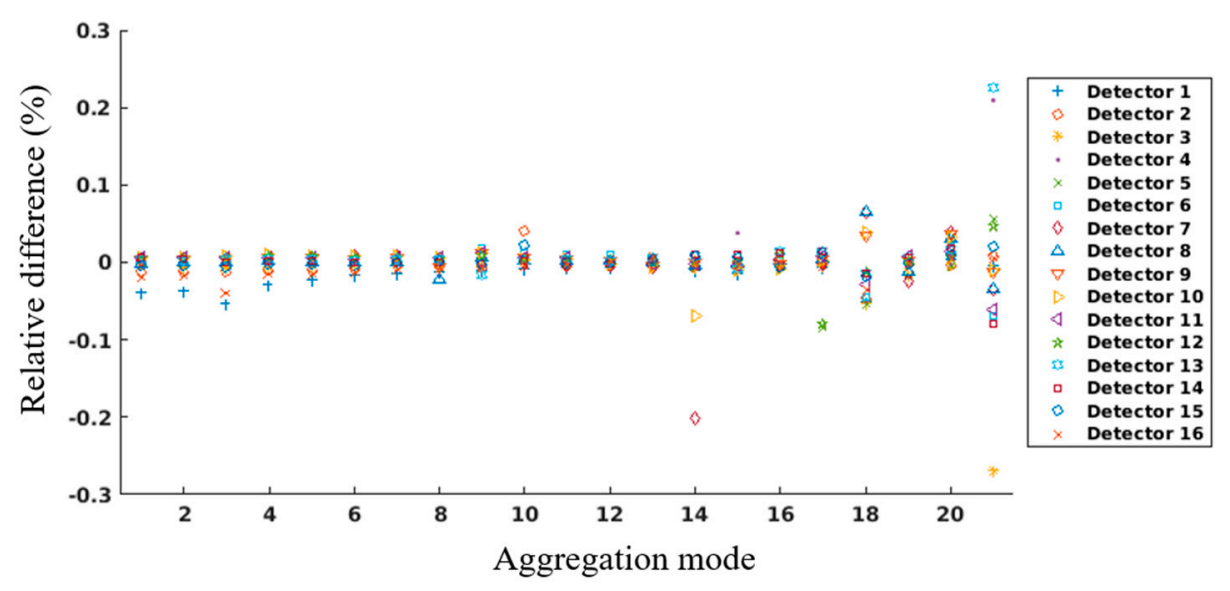

Figure 4. Relative difference between the prelaunch LGS EV gains calculated with a linear fit allowing nonzero constant term and with a linear fit forced through the origin. Data for HAM side A are shown. The relative difference is calculated by $100 \% \times\left(G_{1}-G_{2}\right) / G_{2}$, where $G_{1}$ and $G_{2}$ are the prelaunch LGS EV gains calculated with a linear fit allowing nonzero constant term and with a linear fit forced through the origin respectively.

Figure 5 shows the ratios between the prelaunch LGS EV and SD gains for all 21 aggregation modes. The ratios are close to unity for many aggregation modes and detectors. However, outliers are found in several aggregation modes. The typical examples are detectors 1 and 16 of aggregation modes 9 and 16. Their EV gain values are underestimated by the SD gain values by up to $5 \%$. There are a few detectors and aggregation modes whose EV gain values are overestimated, which are detectors 1 and 16 of aggregation mode 10, detectors 1 and 16 of aggregation mode 12, detectors 1 and 16 of aggregation mode 17, and detector 1 of aggregation mode 18. These outliers suggest non-negligible discrepancy between the LGS EV and SD radiometric responses for a few aggregation modes and detectors. The underestimated or overestimated EV gain values consequently induce either negatively or positively biased radiance values, resulting in dark or bright streaks in NOAA-20 VIIRS DNB imagery. Our analysis of the striping pattern shown in Figure 2a confirmed that those dark and bright streaks are due to the abovementioned detectors and aggregation modes. In particular, the absolute amount of the underestimated EV gain values of detectors 1 and 16 of aggregation modes 9 and 16 are greater than the absolute amount of the overestimated EV gain values of other mentioned detectors and aggregation modes, as illustrated in Figure 5. The dark streaks are much clearer than the bright streaks show in Figure 2a. 


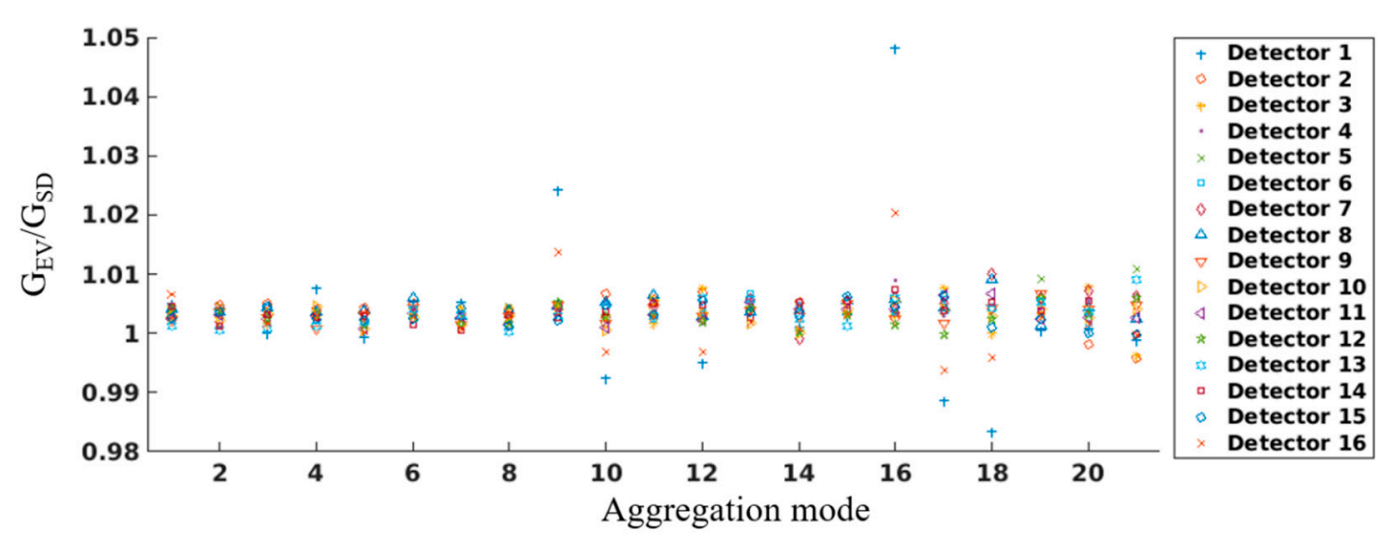

Figure 5. Ratio between the prelaunch LGS EV and SD gain. Data for HAM side A are shown.

When we calculated the prelaunch LGS EV and SD gains, the RVS term was neglected. The LGS EV and SD radiometric responses were measured at the same scan angle in the prelaunch test. The RVS term cancels out when calculating the ratio between two gains, which is the quantity of our concern. It was also noted that the spectral shape of the SIS-100 differs from the solar spectrum due to difference in temperatures [32]. Such spectral mismatch probably yields non-negligible uncertainties in absolute prelaunch gain calibration, especially for broadband sensors like the DNB. However, the uncertainty in the derived ratio between the prelaunch LGS EV and SD gains is considered negligible despite the source difference since it is a relative quantity.

\subsection{Impact of Detector Nonlinearity on Gain Ratio Determination}

The DNB MGS and HGS are designed to observe the Earth during the time of twilight and night when the strength of incident light is much weaker than the light in daytime. The reflected sun light via the SD is too strong for the MGS and HGS gain calibration. As an alternative, their gain coefficients are evaluated by comparing to the adjacent gain stage's gain using simultaneous scenes of the Earth, as summarized in Section 2.

Equation (6) represents the central analytic expressions for the original method to determine the MGS and HGS gains. They are derived using the DNB's linear calibration model Equation (1) which is forced to pass through the origin. In general, the model is applicable for the dynamic range of each gain stage as a whole. The calibrated DNB radiances meet the uncertainty requirement [17]. However, the dynamic range of each DNB's gain stage spans several orders of magnitude. The model fails to accurately characterize local radiometric response in the lower part of the dynamic range. Detector 4/aggregation mode 21 of NOAA-20 VIIRS DNB LGS is known with non-negligible nonlinearity. Figure 6 shows its radiometric response evaluated at different low radiance levels during the prelaunch test. Although the response curve is generally linear, a scrutiny of the curve near the origin indicates that nonlinear response at extremely low radiance level shifts the linear response curve so that it does not pass through the origin. A linear equation that allows nonzero constant term $c_{0}$ is more appropriate to model detector's radiometric response under such circumstance, i.e.,

$$
\mathrm{L}=\mathrm{G} \times\left(\mathrm{DN}-\mathrm{DN}_{0}\right)+\mathrm{c}_{0} .
$$

The radiance range of scenes for gain ratio determination is near the minimal measurable radiance of the lower stage, for example the LGS shown in Figure 1a. Although the specific dataset selected for gain ratio determination is in the linear part of both gain stages dynamic range, it is more appropriate to characterize the simultaneous measurements of two adjacent gain stages by the following equations: 


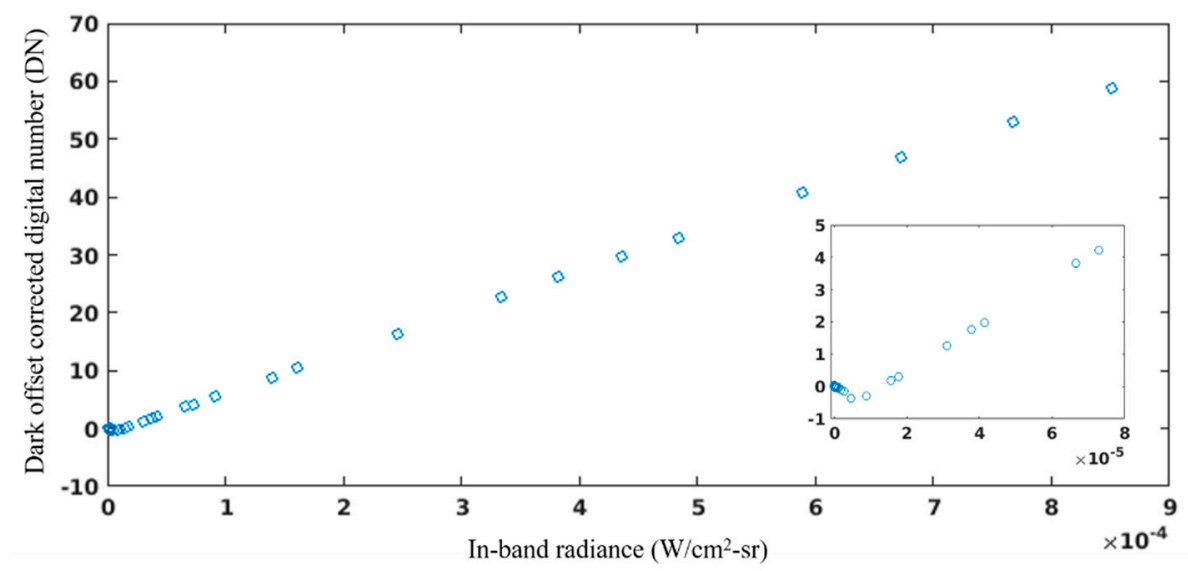

Figure 6. NOAA-20 VIIRS DNB LGS radiometric response (dark offset corrected digital number) at low radiance levels evaluated by using the prelaunch test data. Data for aggregation mode 21, detector 1 and HAM side A are shown. The inset shows the response curve near the origin.

$$
\begin{gathered}
\mathrm{G}_{\mathrm{LGS}} \times \mathrm{dn}_{\mathrm{LGS}}+\mathrm{c}_{0 \mathrm{~L}}=\mathrm{G}_{\mathrm{MGS}} \times \mathrm{dn}_{\mathrm{MGS}}+\mathrm{c}_{0 \mathrm{M}}, \\
\mathrm{G}_{\mathrm{MGS}} \times \mathrm{dn}_{\mathrm{MGS}}+\mathrm{c}_{0 \mathrm{M}}=\mathrm{G}_{\mathrm{HGS}} \times \mathrm{dn}_{\mathrm{HGS}}+\mathrm{c}_{0 \mathrm{H}} .
\end{gathered}
$$

We then have

$$
\begin{aligned}
\mathrm{dn}_{\mathrm{LGS}} & =\mathrm{G}_{\mathrm{MGS} / \mathrm{LGS}} \times \mathrm{dn}_{\mathrm{MGS}}+\frac{\mathrm{c}_{0 \mathrm{M}}-\mathrm{c}_{0 \mathrm{~L}}}{\mathrm{G}_{\mathrm{LGS}}}, \\
\mathrm{dn}_{\mathrm{MGS}} & =\mathrm{G}_{\mathrm{HGS} / \mathrm{MGS}} \times \mathrm{dn}_{\mathrm{HGS}}+\frac{\mathrm{c}_{0 \mathrm{H}}-\mathrm{c}_{0 \mathrm{M}}}{\mathrm{G}_{\mathrm{MGS}}} .
\end{aligned}
$$

$\mathrm{G}_{\text {MGS/LGS }}$ and $\mathrm{G}_{\text {HGS/MGS }}$ can be obtained by linear regression of the selected pairs of $d n_{L G S}$ and $d n_{\text {MGS }}$ and pairs of $d n_{\text {MGS }}$ and dn $n_{\text {HGS }}$. It is noted that Equation (9) reduces to Equation (6) for detectors with negligible nonlinearity at extremely low radiance level as the constant terms $\mathrm{c}_{0 \mathrm{~L}}, \mathrm{c}_{0 \mathrm{M}}$, and $\mathrm{c}_{\mathrm{OH}}$ is zero. However, neglecting the nonzero constant terms for those detectors with significant nonlinearity yields error in the gain ratios evaluated by Equation (6). This can be revealed by substituting Equation (9) to Equation (6), as shown by the following equations:

$$
\begin{gathered}
G_{M G S / L G S}=\frac{d_{L G S}}{d n_{M G S}}+\frac{c_{0 M}-c_{0 L}}{G_{L G S} \times d n_{M G S}}, \\
G_{H G S / M G S}=\frac{d_{M G S}}{d n_{H G S}}+\frac{c_{0 H}-c_{0 M}}{G_{M G S} \times d n_{H G S}} .
\end{gathered}
$$

The calculated $\mathrm{G}_{\text {MGS/LGS }}$ and $\mathrm{G}_{\mathrm{HGS} / \mathrm{MGS}}$ are either positively or negatively biased depending on the sign of the second term on the right-hand side of the equations.

Previous analysis of NOAA-20 VIIRS DNB prelaunch test data shows that several detectors of LGS aggregation mode 21 have non-negligible nonlinearity at extremely low radiance level [18]. It can be anticipated that their values of $\mathrm{G}_{M G S / L G S}$ evaluated by Equation (6) are biased based on the above analysis. Figure 7 shows the scatter plots of $\mathrm{dn}_{\mathrm{LGS}}$ and $\mathrm{dn}_{\mathrm{MGS}}$ for detectors 4 and 6 of aggregation mode 21, using the NOAA-20 VROP data collected on 8 October 2018. The plot for detector 4 is concave up near the origin, suggesting the second term on the right-hand side of Equation (9a) is negative (Figure 7a). As a result, the distribution of $\mathrm{G}_{\mathrm{MGS} / \mathrm{LGS}}$ calculated by the original method Equation (6a) is negatively skewed, while the skewness value is -0.32 (Figure $7 \mathrm{~b}$ ). The plot of detector 6 near the origin shows bending in the opposite direction (Figure 7c). Its distribution of $\mathrm{G}_{M G S / L G S}$ calculated by the original method Equation (6a) is positively skewed, while the skewness value is 0.23 (Figure $7 \mathrm{~d}$ ). We evaluated $\mathrm{G}_{\mathrm{MGS} / \mathrm{LGS}}$ and $\mathrm{G}_{\mathrm{HGS} / \mathrm{MGS}}$ of aggregation mode 21 by processing the NOAA-20 VROP data collected on October 8, 2018 with the original method (Equation 
(6)) and the linear regression method (Equation (9)). The relative difference between two versions of the gain ratios are shown in Figure 8. It can be seen that significant nonlinearities of detectors 4 and 13 of the LGS make their values of GMGS/LGS underestimated by as much as about $13 \%$, yielding dark streaks in the calibrated nighttime imagery as shown in Figure $2 \mathrm{~b}$. The nonlinearities of detectors 6 and 11 of the LGS also bias their values

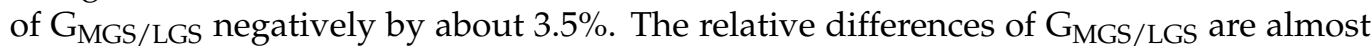
zero for the remaining LGS detectors, suggesting negligible nonlinearity. An example is detector 9 of the LGS. As shown by Figure 1b, its distribution of GMGS/LGS calculated by the original method is almost symmetric, while the skewness value is 0.09 . The relative differences of $\mathrm{G}_{\mathrm{HGS}}$ /MGS shown in Figure $8 \mathrm{~b}$ are close to zero for most detectors, indicating negligible nonlinearity for the MGS detectors of aggregation mode 21.
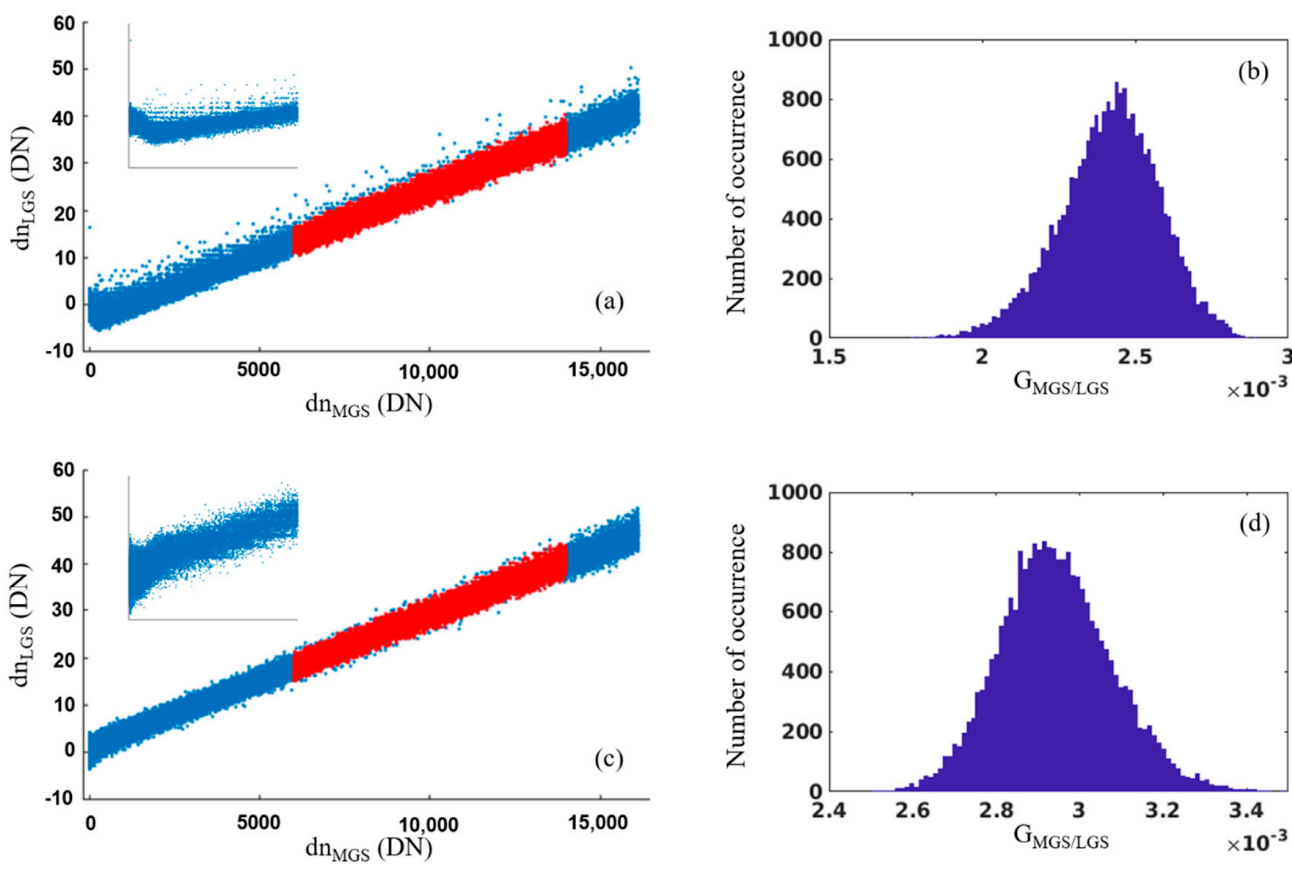

Figure 7. (a) Scatter plot of $d n_{L G S}$ and $d n_{M G S}$ collected by a NOAA-20 VROP between 8:38 and 8:54 UTC on 8 October 2018, for aggregation mode 21 and detector 4 . The inset shows the data points near the origin. (b) Histogram of the gain ratios calculated by the selected pairs of dn $_{\mathrm{LGS}}$ and $\mathrm{dn}_{\mathrm{MGS}}$ [the red part in (a)] using Equation (6a). (c) Scatter plot of $\mathrm{dn}_{\mathrm{LGS}}$ and $\mathrm{dn}_{\mathrm{MGS}}$ collected by a NOAA-20 VROP between 8:38 and 8:54 UTC on October 8, 2018, for aggregation mode 21 and detector 6 . The inset shows the data points near the origin. (d) Histogram of the gain ratios calculated by the selected pairs of $d n_{L G S}$ and $d n_{M G S}$ [the red part in (c)] using Equation (6a).
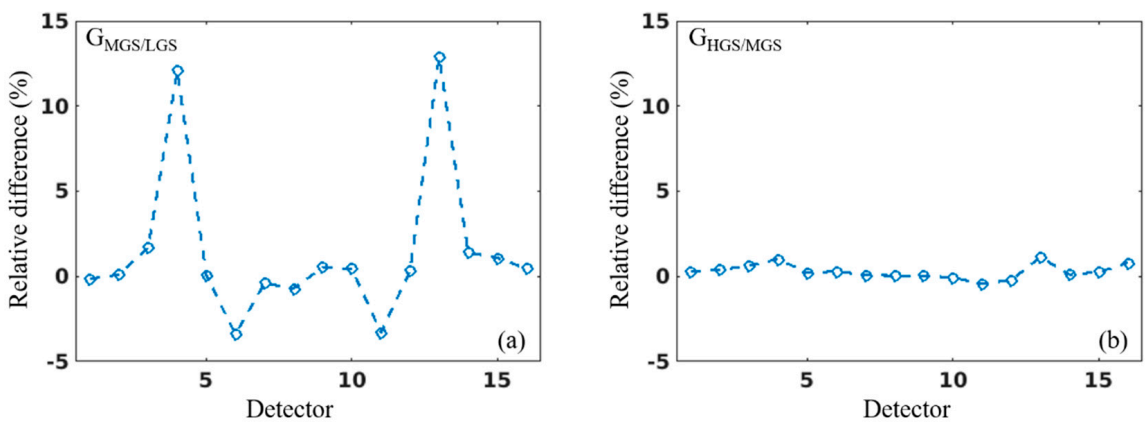

Figure 8. (a) Relative difference between $\mathrm{G}_{\mathrm{MGS} / \mathrm{LGS}}$ determined by linear regression method and the original method. (b) Relative difference between $\mathrm{G}_{\mathrm{HGS}}$ /MGS determined by linear regression method and the original method. Difference $=100 \% \times($ linear regression - original $) /$ original. NOAA-20 VROP data were collected on October 8, 2018, for aggregation mode 21. 


\section{Upgraded DNB Gain Calibration}

Through comprehensive analysis of the NOAA-20 VIIRS DNB gain calibration using both the prelaunch and post-launch data, we have shown that gain coefficient determined by the original calibration method is biased for several aggregation modes and detectors. Consequently, significant striping appears in the calibrated DNB imagery. In this section, we propose an upgraded gain calibration method for correcting the systematic errors and then improving the quality of the NOAA-20 VIIRS DNB imagery.

\subsection{Rescaled LGS Gain by Prelaunch Test Data}

There are two ways to ingest the LGS gain coefficient for generating DNB SDRs at IDPS. One is by the DNB LGS Gains look-up table (LUT), created by offline processing. Update is usually required in case of sensor degradation. The other way is via an automated calibration code called RSBAutoCal [29]. Because it is integrated in the operational processing software, the automatically calculated LGS gain coefficient can be used for generating DNB SDRs in near real time. The LGS gain coefficient either stored in the LUT or produced by RSBAutoCal is determined by using the onboard SD data described in Section 2. Calibration stability of the VIIRS DNB is actively monitored by various methods, including onboard SD [33,34], deep convective clouds [35,36], lunar observations [37-39], and bright stars [40,41]. Unlike the Suomi-NPP VIIRS DNB, the NOAA-20 VIIRS DNB LGS gain is stable since the launch in November 2017. The DNB LGS Gains LUT is adopted for generating NOAA-20 VIIRS DNB SDRs at NOAA IDPS. The last update was in April 2018, which was generated by averaging the coefficients calculated offline with the RSBAutoCal code over several weeks.

As shown in Section 3.1, the LGS gain coefficients of several aggregation modes and detectors determined by the onboard SD data is biased due to discrepancy between the LGS EV and SD radiometric responses. A straightforward way for correcting such biases is to rescale the LGS gain coefficient stored in the LUT by scaling factors derived from the prelaunch test data, i.e.,

$$
\mathrm{G}_{\text {LGS_c }}=\mathrm{S}_{\text {prelaunch }} \times \mathrm{G}_{\text {LGS }}
$$

where the scaling factor $S_{\text {prelaunch }}$ is the ratio of the prelaunch LGS EV and SD gain $\left(\mathrm{G}_{\mathrm{EV}} / \mathrm{G}_{\mathrm{SD}}\right)$ for a given aggregation mode and detector. It can be seen from Figure 5 that the ratios of only a few aggregation modes and detectors differ from one. Their LGS gain coefficients were rescaled by the values of the ratio while the scaling factors are set to be one for the rest of the aggregation modes and detectors. It is worth mentioning that the relatively wide spread of values of $\mathrm{G}_{\mathrm{EV}} / \mathrm{G}_{\mathrm{SD}}$ among detectors is observed for aggregation mode 21 that occupies about $30 \%$ of a NOAA-20 VIIRS DNB image. Considering that a small variation among detectors may be magnified in this large aggregation zone, we rescaled the LGS gain coefficient of all detectors of aggregation mode 21 as well. The scaling factors for updating the NOAA-20 VIIRS DNB LGS Gains LUT are shown in Figure 9.

We reprocessed the NOAA-20 VIIRS DNB daytime image recorded at 8:34 UTC, 14 December 2020 by the updated NOAA-20 VIIRS DNB LGS Gains LUT, shown in Figure 10. Through comparison with the original image shown in Figure 2a, it can be seen that both dark and bright streaks are almost invisible. We also used the streaking metric defined in Ref. [42] to quantitatively evaluate striping of an image. In particular, a relatively uniform area of aggregation zone 16 (white rectangular, Figure 10a) was selected. The streaking metric was calculated by the following equation: 


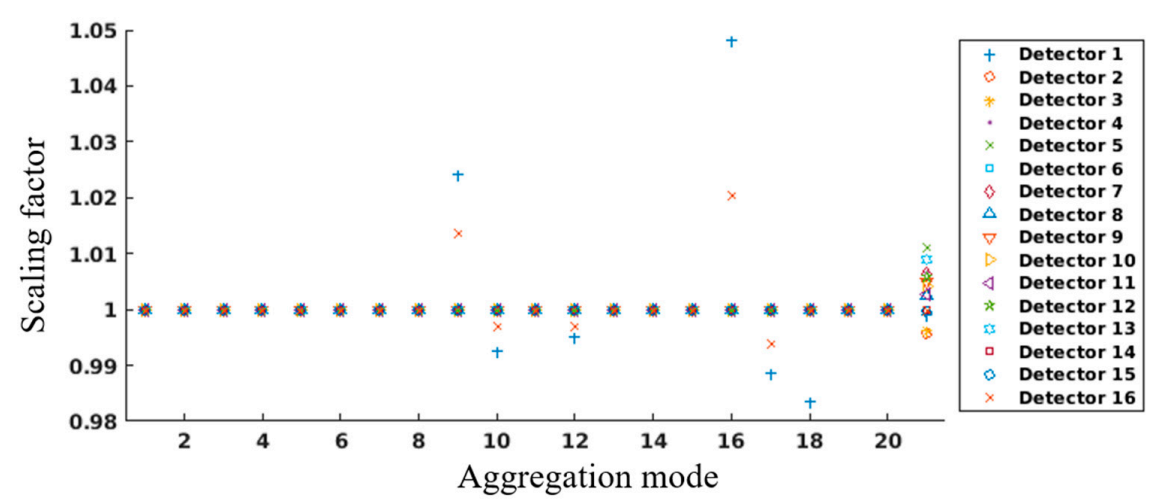

Figure 9. Scaling factors for correcting LGS gain coefficient stored in the NOAA-20 VIIRS DNB LGS Gains LUT.

$$
S_{i}=\frac{\left|\bar{L}_{i}-0.5 \times\left(\bar{L}_{i-1}+\bar{L}_{i+1}\right)\right|}{\bar{L}_{i}} \times 100 \%,
$$

where $\bar{L}_{i}$ is the average radiance of the ith scan line of a given aggregation zone. The maximum streaking metric value has been reduced from about 3.5\% in the original image to about $0.5 \%$ in the reprocessed image. As noted in [42], streaks become apparent in a homogeneous unaltered image when its streaking metric is around $0.25 \%$. The streaking metric of our reprocessed image is close to this threshold, suggesting the effectiveness of the updated LGS Gains LUT.

Comparison of the aggregation zone 21 of a NOAA-20 VIIRS DNB daytime image and its reprocessed version, illustrated by Figure 11, also shows striping reduction by using the updated LGS Gains LUT. According to Equations (1) and (4), the bias in the LGS gain propagates to the HGS gain, yielding striping in nighttime imagery. An example is shown in Figure 12a, where the dark streaks on the right side of the image are the scan lines of detectors 1 and 16 of aggregation zone 16. They are successfully minimized in the reprocessed image (Figure 12b) though bright streaks in the adjacent aggregation zone remain. We have also tested the updated NOAA-20 VIIRS DNB LGS Gains LUT by reprocessing selective NOAA-20 VIIRS DNB daytime granules from early mission to present. These granules are over large and relatively uniform areas on Earth, such as deserts and deep convective clouds, which are favorable for evaluating DNB image quality. The radiance magnitudes of these selected granules are from $10^{-3}$ to $10^{-2} \mathrm{~W} / \mathrm{cm}^{2}$-sr, the typical radiance range of DNB daytime scenes. Striping in these images has been successfully removed or reduced by the updated NOAA-20 VIIRS DNB LGS Gains LUT. 


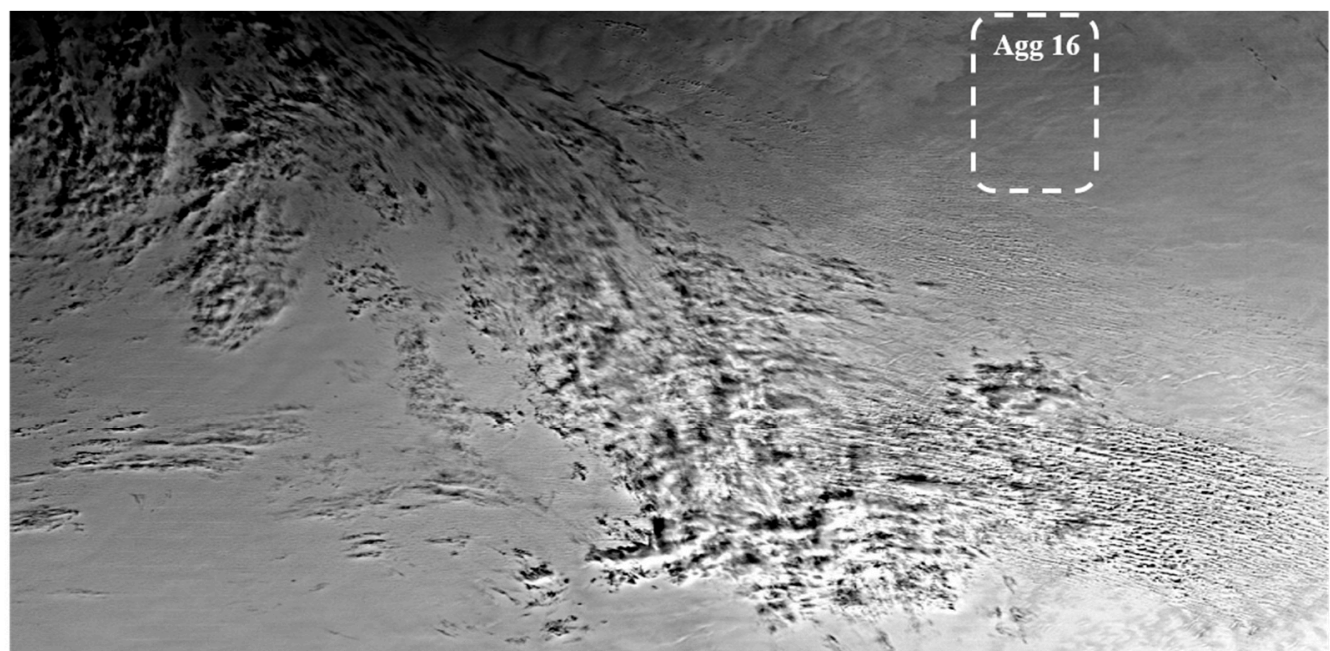

(a)

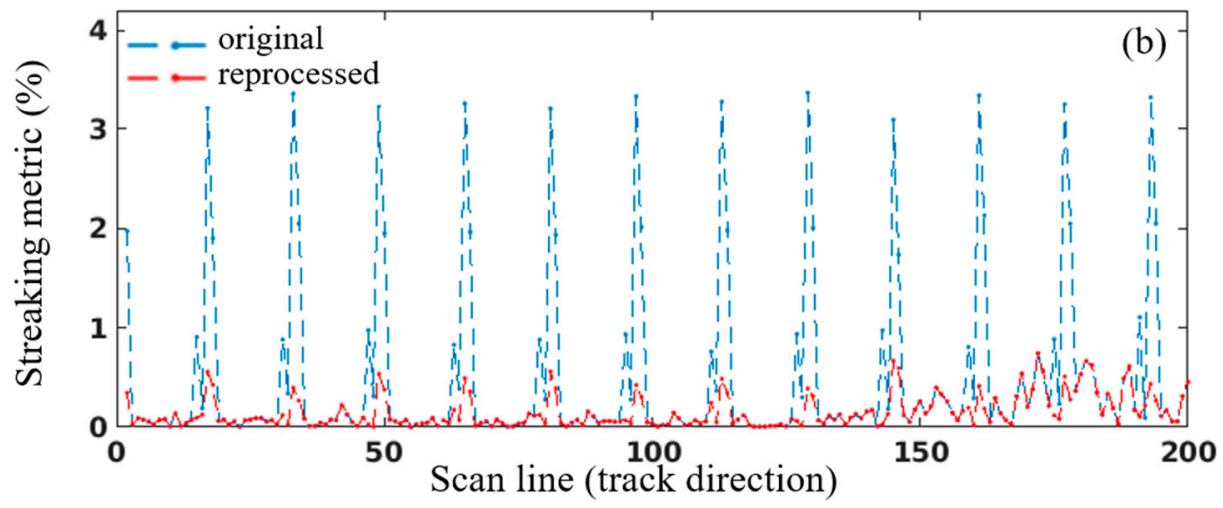

Figure 10. (a) Reprocessed NOAA-20 VIIRS DNB daytime image recorded over Antarctica at 8:34 UTC, 14 December 2020. The $768 \times 768$ (track $\times$ scan) pixels are on the right side of the granule (aggregation zones 8-19). The updated NOAA-20 VIIRS DNB LGS Gains LUT was used for reprocessing. (b) Streaking metrics of the original (Figure 2a) and reprocessed (Figure 10a) radiance along the selected scan lines within aggregation zone 16 on the right side of the granule (white rectangular). 

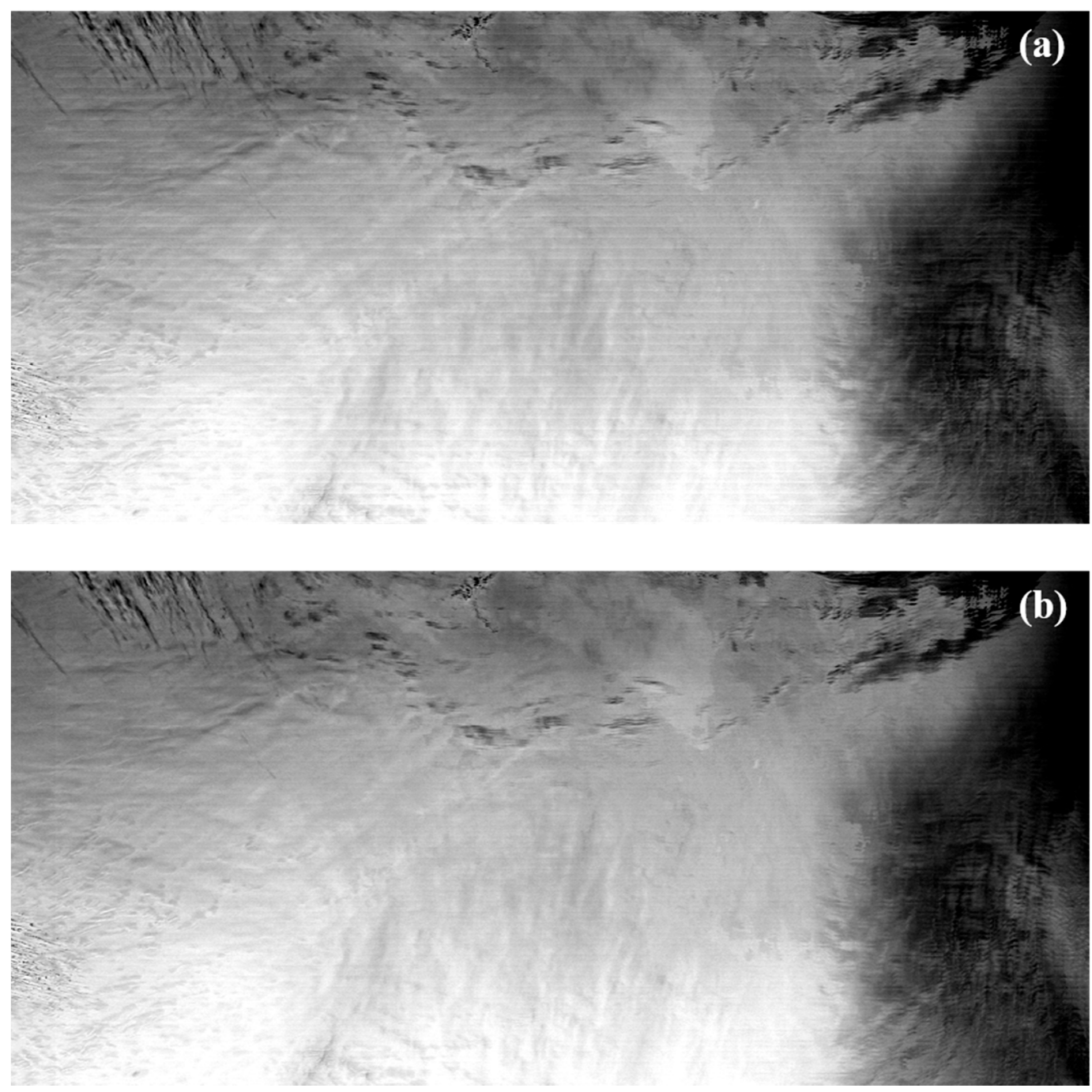

Figure 11. (a) Original NOAA-20 VIIRS DNB daytime image recorded over Antarctica at 8:34 UTC, 14 December 2020. The $768 \times 768$ (track $\times$ scan) pixels are on the right side of the granule (aggregation zone 21). (b) Reprocessed image using the updated NOAA-20 VIIRS DNB LGS Gains LUT.
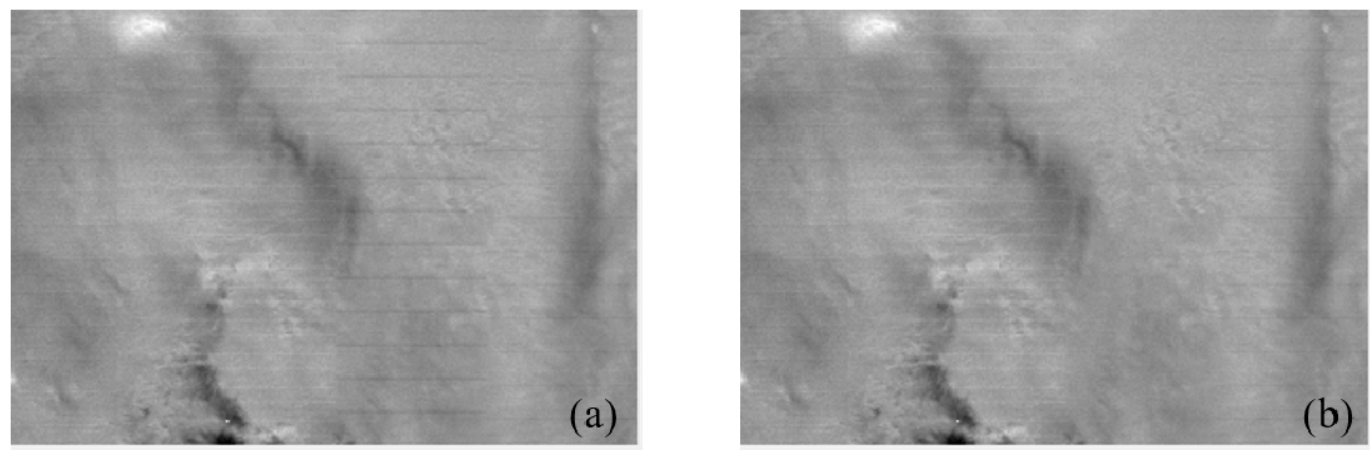

Figure 12. (a) Original NOAA-20 VIIRS DNB nighttime image recorded over North America at 8:13 UTC, 29 December 2020. The $208 \times 296$ (track $\times$ scan) pixels are in the upper left side of the granule (aggregation zones 15-19). (b) Reprocessed image using the updated NOAA-20 VIIRS DNB LGS Gains LUT. 


\subsection{Gain Ratio Determination by Linear Regression}

Similar to the LGS gains, the MGS/LGS and HGS/MGS gain ratios can also be ingested to the operational processing software either from the VIIRS DNB Gain Ratios LUT or RSBAutoCal. However, the values of the gain ratios stored in the VIIRS DNB gain ratios LUT are evaluated by the DNB EV data collected through the VROPs, while RSBAutoCal uses the data of the DNB OBC calibrators to calculate the gain ratios. At NOAA IDPS, the operational NOAA-20 VIIRS DNB SDRs are generated using the NOAA-20 VIIRS DNB Gain Ratios LUT, which is updated monthly by processing the VROP data collected during each new moon night.

As discussed in Section 3.2, the gain ratio values determined by the original method (Equation (6)) are biased for those detectors with non-negligible nonlinearity at extreme low radiance level. We corrected these errors by processing the VROP data with the linear regression method. The specific steps are summarized in the following

1. Calculate dark offset corrected counts of all three gain stages, $\mathrm{dn}_{\mathrm{LGS}}, \mathrm{dn}_{\mathrm{MGS}}$, and dn HGS. $_{\text {. }}$

2. For a given aggregation mode and detector, create an ensemble of $d_{\text {LGS }}$ and $d n_{M G S}$ (or $\mathrm{dn}_{\mathrm{MGS}}$ and $\mathrm{dn}_{\mathrm{HGS}}$ ) and then remove outliers by a filter scheme.

3. Evaluate $\mathrm{G}_{\text {MGS/LGS }}$ (or $\mathrm{G}_{\mathrm{HGS} / \mathrm{MGS}}$ ) by a liner fit of the filtered ensemble of $\mathrm{dn}_{\mathrm{LGS}}$ and $\mathrm{dn}_{\mathrm{MGS}}$ (or $\mathrm{dn}_{\mathrm{MGS}}$ and $\mathrm{dn}_{\mathrm{HGS}}$ ) that allows nonzero constant term (Equation (9)).

We reprocessed the NOAA-20 VIIRS DNB nighttime granule collected at 8:56 UTC, October 24, 2018 using the new DNB gain ratios algorithm as well as the updated LGS Gain LUT. It can be clearly seen from Figure 13 that dark streaks disappear in the reprocessed version. Figure 14 show the histogram of the radiances of aggregation zone 21 of the NOAA-20 VIIRS DNB nighttime granules collected between 8:50 UTC and 9:10 UTC, October 24, 2018. The plots of detectors 4, 6, 11, and 13, which are out of family in the original version, are in family with the rest of the detectors in the reprocessed version.

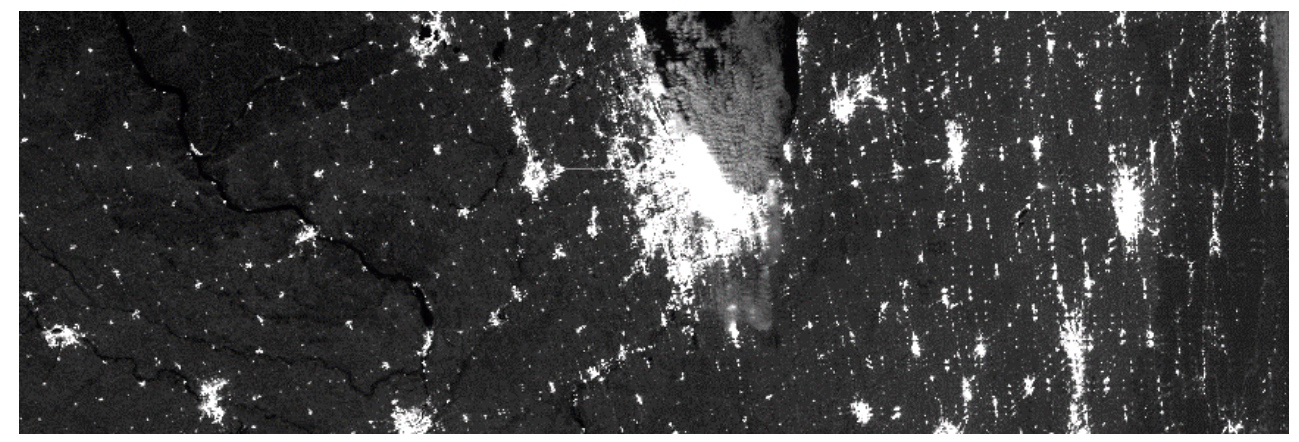

Figure 13. Reprocessed NOAA-20 VIIRS DNB nighttime image recorded over the Midwestern United States at 8:56 UTC, 24 October 2018. The $288 \times 864$ (track $\times$ scan) pixels are in the upper right side of the granule. The updated NOAA-20 VIIRS DNB LGS Gains LUT and the NOAA-20 VIIRS DNB Gain Ratios LUT created by the linear regression method were used for reprocessing. 

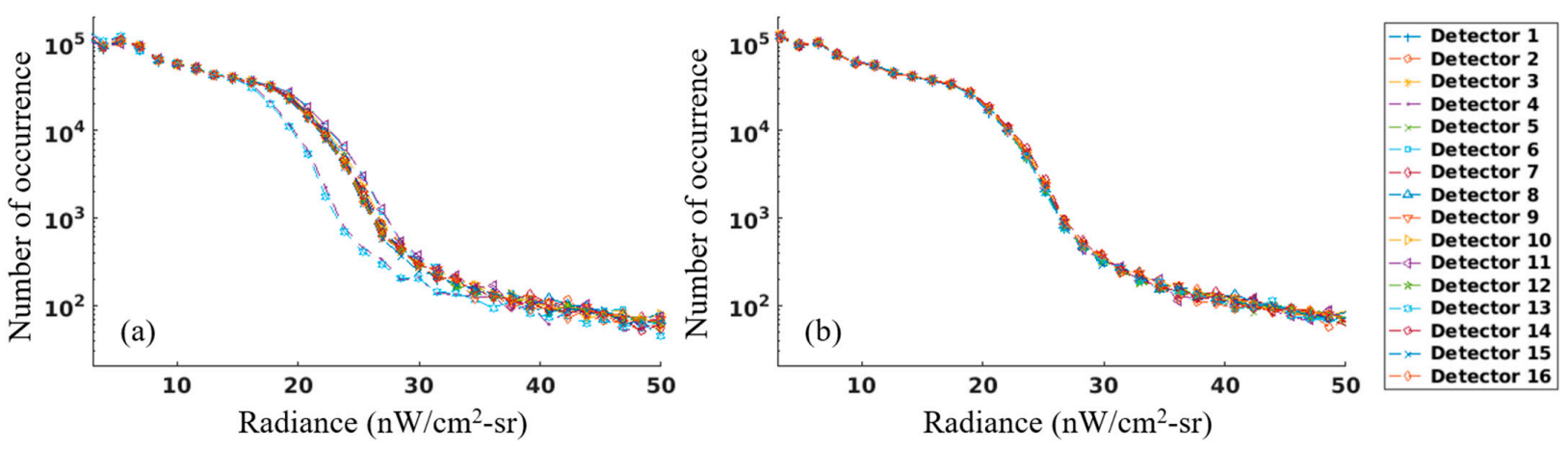

Figure 14. Histogram of the radiances of aggregation zone 21 of the NOAA-20 VIIRS DNB nighttime granules collected between 8:50 UTC and 9:10 UTC, 24 October 2018. (a) The nighttime imagery was created by the original NOAA-20 VIIRS DNB Gain Ratios LUT. (b) The nighttime imagery was created by the updated NOAA-20 VIIRS DNB Gain Ratios LUT.

\section{Conclusions}

In this paper, we thoroughly analyzed the DNB gain calibration process using the NOAA-20 VIIRS DNB prelaunch and post-launch data. It is found that the LGS gain coefficients calculated from the onboard SD data are biased for a few aggregation modes and detectors due to discrepancy between the DNB LGS EV and SD radiometric responses. Errors also exist in the MGS/LGS gain ratios obtained by the original method for the detectors with non-negligible nonlinearity at extremely low radiance level. These systematic errors yield striping in the NOAA-20 VIIRS DNB imagery from both daytime and nighttime.

With the acquired knowledge, we improved the gain calibration for the NOAA-20 VIIRS DNB. In particular, the operational LGS gain calibration errors are corrected by applying the scaling factors derived from the prelaunch test data. The linear regression method is adopted for determining the gain ratios. The upgraded gain calibration has been implemented in the operational calibration of the NOAA-20 VIIRS DNB at NOAA IDPS for the gain ratios since November 2018 and for the LGS gains since February 2021. Striping in the NOAA-20 VIIRS DNB daytime and nighttime imagery generated is thereby significantly reduced. It is noted that stripping in the NOAA-20 VIIRS DNB NCC imagery has been reduced as well after the implementation of the upgraded gain calibration. The improved quality of the NOAA_20 VIIRS DNB imagery will also benefit studies of the nighttime light characteristics [43,44]. The upgraded method can be used for gain calibration of the VIIRS DNB onboard future Joint Polar Satellite Systems (JPSS) satellites, as well as reprocessing of the Suomi-NPP and NOAA-20 VIIRS DNB data.

It is worth noting that some striping is still observed in the operational NOAA-20 VIIRS DNB imagery after the implementation of the upgraded gain calibration method, for example, in aggregation zone 21 of daytime radiance images collected near twilight regions. On-orbit DNB gain calibration is complex because of the large dynamic range of each gain stage. The aforementioned striping in aggregation zone 21 of a daytime image occurs at a low radiance level where the linear calibration model as shown by Equation (1) is not accurate enough to characterize the radiometric response at this radiance level. The complex aggregation scheme is another reason. The DNB's sensor contains hundreds (LGS) to thousands (HGS) subpixels. Variations in radiometric response among individual subpixels are unavoidable. Such variability propagates to the virtual DNB detectors after aggregation, while the number of subpixels grouped in an aggregation zone varies following the aggregation scheme. Non-uniformity is discovered in a few aggregation zones and at many aggregation zone boundaries [17]. Developing a model that can characterize the DNB's radiometric response of the whole dynamic range for all aggregation zones and detectors is needed for further improving DNB image quality in the future. 
Author Contributions: Conceptualization, Y.G.; Data curation, Y.G., S.B., W.W., S.U., T.C., X.S. and B.Z.; Formal analysis, Y.G.; Investigation, Y.G.; Methodology, Y.G.; Software, S.B. and B.Z.; Supervision, C.C.; Writing—original draft, Y.G.; Writing-review \& editing, S.B., W.W., S.U., T.C., X.S., B.Z. and C.C. All authors have read and agreed to the published version of the manuscript.

Funding: This research was funded by the PROTECH contract awarded to Global Science \& Technology (GST) by NOAA/National Environmental Satellite, Data, and Information Service (NESDIS).

Conflicts of Interest: The authors declare no conflict of interest.

Disclamier: The scientific results and conclusions, as well as any views or opinions expressed herein, are those of the author(s) and do not necessarily reflect those of NOAA or the Department of Commerce.

\section{References}

1. Miller, S.D.; Mills, S.P.; Elvidge, C.D.; Lindsey, D.T.; Lee, T.F.; Hawkins, J.D. Suomi satellite brings to light a unique frontier of nighttime environmental sensing capabilities. Proc. Natl. Acad. Sci. USA 2012, 109, 15706-15711. [CrossRef]

2. Miller, S.D.; Straka, W., III; Mills, S.P.; Elvidge, C.D.; Lee, T.F.; Solbrig, J.; Walther, A.; Heidinger, A.K.; Weiss, S.C. Illuminating the capabilities of the Suomi National Polar-Orbiting Partnership Visible Infrared Imaging Radiometer Suite Day/Night Band. Remote Sens. 2013, 5, 6717-6766. [CrossRef]

3. Cao, C.; Shao, X.; Uprety, S. Detecting light outages after severe storms using the S-NPP/VIIRS Day/Night Band radiances. IEEE Geosci. Remote Sens. Lett. 2013, 10, 1582-1586. [CrossRef]

4. Elvidge, C.D.; Zhizhin, M.; Baugh, K.; Hsu, F.C. Automatic boat identification system for VIIRS low light imaging data. Remote Sens. 2015, 7, 3020-3036. [CrossRef]

5. McHardy, T.M.; Zhang, J.; Reid, J.S.; Miller, S.D.; Hyer, E.J.; Kuehn, R.E. An improved method for retrieving nighttime aerosol optical thickness from the VIIRS Day/Night Band. Atmos. Meas. Tech. 2015, 8, 4773-4783. [CrossRef]

6. Jing, X.; Shao, X.; Cao, C.; Fu, X.; Yan, L. Comparison between the Suomi-NPP Day-Night Band and DMSP-OLS for correlating socio-economic variables at the provincial level in China. Remote Sens. 2016, 8, 17. [CrossRef]

7. Elvidge, C.D.; Baugh, K.; Zhizhin, M.; Hsu, F.C.; Ghosh, T. VIIRS night-time lights. Int. J. Remote Sens. 2017, 38 , 5860-5879. [CrossRef]

8. Román, M.O.; Wang, Z.; Sun, Q.; Kalb, V.; Miller, S.D.; Molthan, A.; Schultz, L.; Bell, J.; Stokes, E.C.; Pandey, B.; et al. NSAS's Black Marble nighttime lights product suite. Remote Sens. Environ. 2018, 210, 113-143. [CrossRef]

9. Zhao, M.; Zhou, Y.; Li, X.; Cao, W.; He, C.; Yu, B.; Li, X.; Elvidge, C.D.; Cheng, W.; Zhou, C. Applications of satellite remote sensing of nighttime light observations: Advanced, challenges, and perspectives. Remote Sens. 2019, 11, 1971. [CrossRef]

10. Levin, N.; Kyba, C.C.M.; Zhang, Q.; Sánchez de Miguel, A.; Román, M.O.; Li, X.; Portnov, B.A.; Molthan, A.L.; Jechow, A.; Miller, S.D.; et al. Remote sensing of night lights: A review and an outlook for the future. Remote Sens. Environ. 2020, 237, 111443. [CrossRef]

11. Liang, C.K.; Mills, S.; Hauss, B.I.; Miller, S.D. Improved VIIRS Day/Night Band imagery with near-constant contrast. IEEE Trans. Geosci. Remote Sens. 2014, 52, 6964-6971. [CrossRef]

12. Hillger, D.; Kopp, T.; Seaman, C.; Miller, S.; Lindsey, D.; Stevens, E.; Solbrig, J.; Straka, W.; Kreller, M.; Kuciauskas, A.; et al. User validation of VIIRS satellite imagery. Remote Sens. 2016, 8, 11. [CrossRef]

13. Visible Infrared Imaging Radiometer Suite (VIIRS) Sensor Data Record (SDR) User's Guide. Available online: https:/ /www.star. nesdis.noaa.gov/jpss/documents/UserGuides/VIIRS_SDR_Users_Guide.pdf (accessed on 18 June 2021).

14. Mills, S.; Miller, S.D. VIIRS Day-Night Band calibration methods for improved uniformity. Proc. SPIE 2014, $9218,921809$.

15. Baugh, K.; Hsu, F.C.; Elvidge, C.; Zhizhin, M. Nighttime lights compositing using the VIIRS Day-Night Band: Preliminary results. Proc. Asia Pac. Adv. Netw. 2013, 35, 70-86. [CrossRef]

16. Wang, W.; Cao, C. NOAA-20 VIIRS DNB aggregation mode change: Prelaunch efforts and on-orbit verification/validation results. IEEE J. Sel. Top. Appl. Earth Obs. Remote Sens. 2019, 12, 2015-2023. [CrossRef]

17. Schwarting, T.; McIntire, J.; Oudrari, H.; Xiong, X. JPSS-1/NOAA-20 VIIRS day-night band prelaunch radiometric calibration and performance. IEEE Trans. Geosci. Remote Sens. 2019, 57, 7534-7546. [CrossRef]

18. Mills, S.; Miller, S. VIIRS Day/Night Band—correcting striping and nonuniformity over a very large dynamic range. J. Imaging 2016, 2, 9. [CrossRef]

19. Shao, X.; Liu, T.; Uprety, S.; Wang, W.; Zhang, B.; Cao, C. A light contamination ranking index-based method for automating VIIRS Day/Night Bnad stray light correction. Proc. SPIE 2018, 10764, 107641I.

20. Chen, H.; Xiong, X.; Geng, X.; Twedt, K. Stray-light correction and prediction for Suomi National Polar-orbiting Partnership Visible Infrared Imaging Radiometer Suite Day-Night Band. J. Appl. Remote Sens. 2019, 13, 024521. [CrossRef]

21. Joint Polar Satellite System VIIRS Radiometric Calibration Algorithm Theoretical Basis Document. Available online: https: //www.star.nesdis.noaa.gov/jpss/documents /ATBD/D0001-M01-S01-003_JPSS_ATBD_VIIRS-SDR_D.pdf (accessed on 18 June 2021). 
22. Xiong, X.; Butler, J.; Chiang, K.; Efremova, B.; Fulbright, J.; Lei, N.; McIntire, J.; Oudrari, H.; Sun, J.; Wang, Z.; et al. VIIRS on-orbit calibration methodology and performance. J. Geophys. Res. Atmos. 2014, 119, 5065-5078. [CrossRef]

23. Joint Polar Satellite System VIIRS Geolocation Algorithm Theoretical Basis Document. Available online: https://www.star.nesdis. noaa.gov/jpss/documents / ATBD/D0001-M01-S01-004_JPSS_ATBD_VIIRS-Geolocation_A.pdf (accessed on 18 June 2021).

24. Geis, J.; Florio, C.; Moyer, D.; Rausch, K.; De Luccia, F. VIIRS Day-Night Band gain and offset determination and performance. Proc. SPIE 2012, 8510, 851012.

25. Uprety, S.; Cao, C.; Gu, Y.; Shao, X.; Blonski, S.; Zhang, B. Calibration Improvements in S-NPP VIIRS DNB sensor data record using version 2 reprocessing. IEEE Trans. Geosci. Remote Sens. 2019, 57, 9602-9611. [CrossRef]

26. Gu, Y.; Uprety, S.; Blonski, S.; Zhang, B.; Cao, C. Improved algorithm for determining the Visible Infrared Imaging Radiometer Suite Day/Night Band high-gain stage dark offset free from light contamination. Appl. Opt. 2019, 58, 1400-1407. [CrossRef]

27. Sun, J.; Wang, M. Optimized calibration methodology of VIIRS day-night band low-gain stage using a solar diffuser. Appl. Opt. 2017, 56, 4433-4442. [CrossRef] [PubMed]

28. Lee, S.; McIntire, J.; Oudrari, H.; Schwarting, T.; Xiong, X. A new method for Suomi-NPP VIIRS day-night band on-orbit radiometric calibration. IEEE Trans. Geosci. Remote Sens. 2015, 53, 324-334.

29. Rausch, K.; Houchin, S.; Cardema, J.; Moy, G.; Haas, E.; De Luccia, F.J. Automated calibration of the Suomi National Polar-Orbiting Partnership (S-NPP) Visible Infrared Imaging Radiometer Suite (VIIRS) reflective solar bands. J. Geophys. Res. Atmos. 2013, 118, 13434-13442. [CrossRef]

30. Oudrari, H.; McIntire, J.; Xiong, X.; Butler, J.; Ji, Q.; Schwarting, T.; Lee, S.; Efremova, B. JPSS-1 VIIRS radiometric characterization and calibration based on pre-launch testing. Remote Sens. 2016, 8, 41. [CrossRef]

31. Lee, S.; Wang, W.; Cao, C. JPSS-1 VIIRS DNB nonlinearity and its impact on SDR calibration. Proc. SPIE 2015, $9607,960717$.

32. Xiong, X.; Butler, J. Challenges and approaches for sensor reflective solar calibration. In Proceedings of the 2019 IEEE International Geoscience and Remote Sensing Symposium (IGARSS), Yokohama, Japan, 28 July-2 August 2019; IEEE: Piscataway, NJ, USA, 2019; pp. 5796-5799.

33. Chen, H.; Xiong, X.; Sun, C.; Chen, X.; Chiang, K. Suomi-NPP VIIRS day-night Band on-orbit calibration and performance. J. Appl. Remote Sens. 2017, 11, 036019. [CrossRef]

34. Chen, H.; Xiong, X.; Link, D.O.; Sun, C. NOAA-20 Visible Infrared Imaging Radiometer Suite day-night Band on-orbit calibration and performance. J. Appl. Remote Sens. 2020, 14, 034516. [CrossRef]

35. Wang, W.; Cao, C. Monitoring the NOAA operational VIIRS RSB and DNB calibration stability using monthly and semi-monthly deep convective clouds time series. Remote Sens. 2016, 8, 32. [CrossRef]

36. Cao, C.; Bai, Y.; Wang, W.; Choi, T. Radiometric inter-consistency of VIIRS DNB on Suomi NPP and NOAA-20 from observations of reflected lunar lights over deep convective clouds. Remote Sens. 2019, 11, 934. [CrossRef]

37. Wang, Z.; Xiong, X.; Fulbright, J.; Lei, N. VIIRS Day/Night Band radiometric calibration stability monitoring using the Moon. J. Geophys. Res. Atmos. 2017, 122, 5616-5624. [CrossRef]

38. Choi, T.; Cao, C.; Xi, S. NOAA-20 Visible Infrared Imaging Radiometer Suite (VIIRS) Day-Night Band calibration using the scheduled lunar collections. In Proceedings of the 2020 IEEE International Geoscience and Remote Sensing Symposium (IGARSS), Virtual Symposium. 26 September-2 October 2020; IEEE: Piscataway, NJ, USA, 2019; pp. 6047-6050.

39. Choi, T.; Cao, C. S-NPP VIIRS Day Night Band on-board solar diffuser calibration validation using the scheduled lunar collections. Remote Sens. 2021, 13, 1093. [CrossRef]

40. Wilson, T.; Xiong, X. Intercomparison of the SNPP and NOAA-20 VIIRS DNB high-gain stage using observations of bright stars. IEEE Trans. Geosci. Remote Sens. 2020, 58, 8038-8045. [CrossRef]

41. Wilson, T.; Xiong, X. Performance assessments of the SNPP and N20 VIIRS DNB using observations of bright stars. Proc. SPIE 2020, 11530, 1153015.

42. Pesta, F.; Bhatta, S.; Helder, D.; Mishra, N. Radiometric non-uniformity characterization and correction of Landsat 8 OLI using Earth imagery-based techniques. Remote Sens. 2015, 7, 430-446. [CrossRef]

43. Li, X.; Ma, R.; Zhang, Q.; Li, D.; Liu, S.; He, T.; Zhao, L. Anisotropic characteristic of artificial light at night-Systematic investigation with VIIRS DNB multi-temporal observations. Remote Sens. Environ. 2019, 233, 111357. [CrossRef]

44. Tong, K.P.; Kyba, C.C.M.; Heygster, G.; Kuechly, H.U.; Notholt, J.; Kolláth, Z. Angular distribution of upwelling artificial light in Europe as observed by Suomi-NPP satellite. J. Quant. Spectrosc. Radiat. Transf. 2020, 249, 107009. [CrossRef] 